
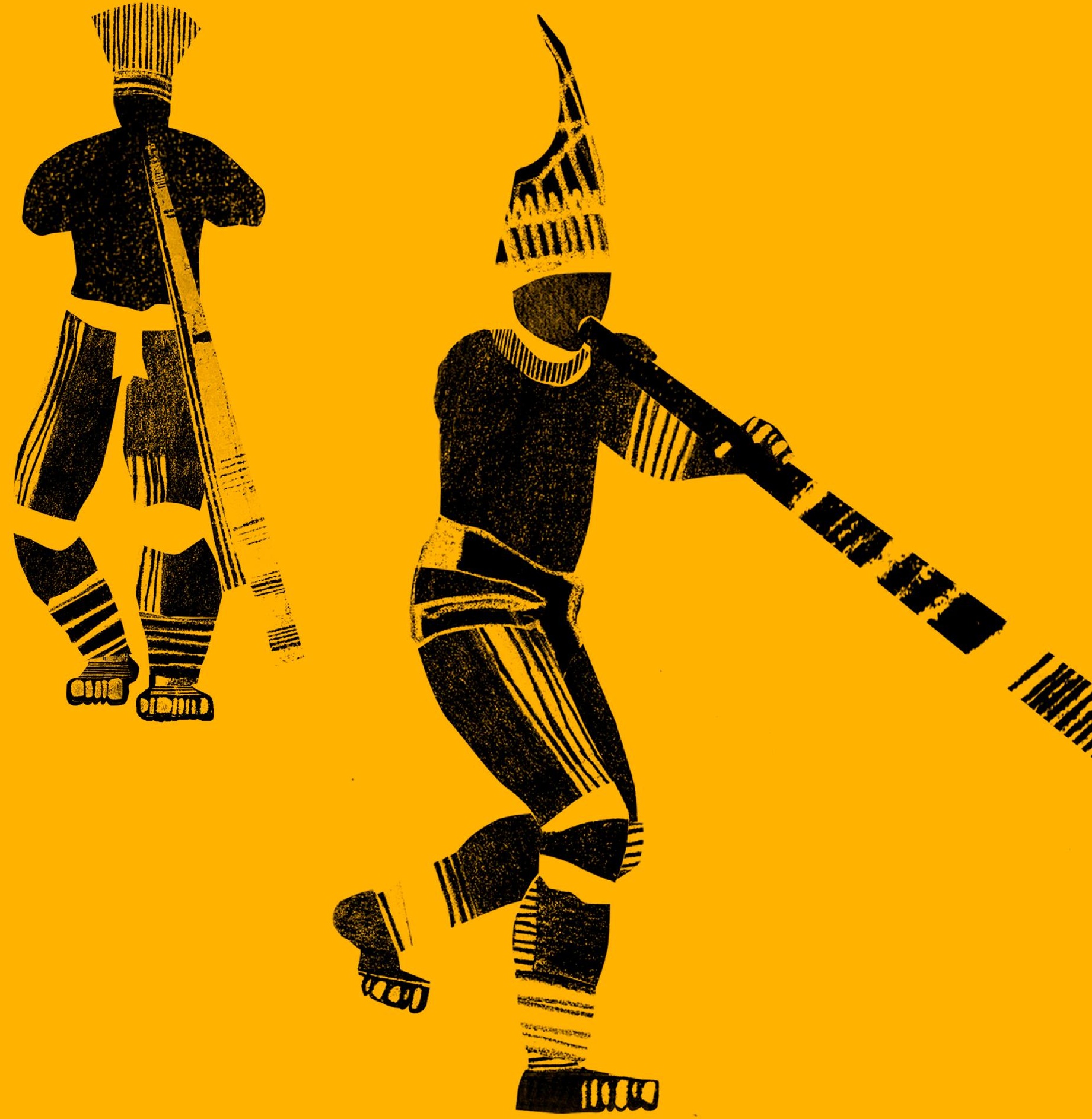


\title{
Circulando imagens e tecendo redes no Território Indígena do Xingu
}

\author{
Luiza Serber ${ }^{l}$
}

\section{Resumo}

Guiada pela busca por apreender as dinâmicas de produção e circulação imagética no universo xinguano, transitei por diferentes regiões da bacia do Rio Xingu, presenciando variadas situações nas quais a produção audiovisual assume nas aldeias uma posição central. Nessa trajetória, Alto, Médio e Baixo Xingu emaranhavam-se numa trama costurada por variadas formas de fazer, pensar, ver e circular filmes - transpondo, assim, limites convencionalmente sustentadas pela etnologia da região. A presente reflexão se constitui como um esforço por tecer um conjunto heterogêneo de observações que resultam de uma série de incursões a alguns dos povos que hoje integram o Território Indígena do Xingu (TIX). Nesse ensaio, procuro delinear os contornos de um circuito imagético que se configura entre as diferentes aldeias xinguanas e que, sugiro, gera efeitos sobre as relações que vigoram entre entre os povos do TIX. A partir de minhas observações de campo, proponho que a rede regional xinguana encontra-se hoje "amarrada", não apenas por trocas comerciais, casamentos, acusações de feitiçaria e experiências políticas conjuntas, mas, também, por uma experiência partilhada de uso do vídeo.

Palavras-Chave: Xingu; Mídia Indígena; Cinema Indígena; Circuitos Imagéticos; Audiovisual.

\begin{abstract}
In search of apprehending the dynamics of image production and circulation among Xinguano people, I traveled through different regions of the Xingu River basin, witnessing various situations in which audiovisual production takes a central position in the villages. In this trajectory, Upper, Middle and Lower Xingu were entwined in a weave sewn by various ways of making, thinking, watching and circulating films - thus crossing borders conventionally underpinned by the ethnology of the region. The present reflection is an effort to weave a heterogeneous set of observations that result from a series of incursions to some of the peoples that today integrate the Xingu Indigenous Territory (TIX). In this essay, I seek to delineate the contours of an imagetic circuit that is configured among the different Xinguano villages and that, I suggest, generates effects on the relations that are established among the peoples within the Territory. Based on my field observations, I suggest that the Xinguano regional network is nowadays "tied", not only by commercial exchanges, marriages, witchcraft accusations and joint political experiences, but, also, by a shared experience of using video.
\end{abstract}

Keywords: Xingu; Indigenous Media; Indigenous Cinema; Imagetic Circuits; Audiovisual. 


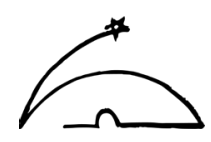

\section{Apresentação}

Guiada pela busca por apreender as dinâmicas de produção e circulação imagética no universo xinguano, transitei por diferentes regiões da bacia do Rio Xingu, presenciando variadas situações nas quais a produção audiovisual assume nas aldeias uma posição central. Nessa trajetória, Alto, Médio e Baixo Xingu emaranhavam-se numa trama costurada por variadas formas de fazer, pensar, ver e circular filmes - transpondo, assim, limites convencionalmente sustentadas pela etnologia da região. A presente reflexão se constitui como um esforço por tecer um conjunto heterogêneo de observações que resultam de uma série de incursões a alguns dos povos que hoje integram o Território Indígena do Xingu (TIX). Nesse ensaio, procuro delinear os contornos de um circuito imagético que se configura entre as diferentes aldeias xinguanas e que, sugiro, gera efeitos sobre as relações que vigoram entre entre os povos do TIX. A partir de minhas observações de campo, proponho que a rede regional xinguana encontra-se hoje "amarrada", não apenas por trocas comerciais, casamentos, acusações de feitiçaria e experiências políticas conjuntas ${ }^{2}$, mas, $^{2}$ também, por uma experiência partilhada de uso do vídeo.

Desde esta perspectiva, convido o leitor a pensar que se Menezes Bastos (1978) sugeria - há quatro décadas - que o ritual (em especial, a música) figura enquanto língua franca do complexo multilíngue alto-xinguano, talvez seja possível, hoje, esboçar uma concepção do vídeo enquanto uma espécie de língua franca do - mais amplo - Território Indígena do Xingu. Uma vez que o tema das especialidades produtivas alto-xinguanas ${ }^{3}$, e o sistema de trocas que as move, já se encontra consolidado no campo da etnologia, parece-me legítimo e profícuo começarmos a pensar, analogamente, na progressiva constituição de um sistema de trocas que se estende por todas as regiões do TIX e por meio do qual se trocam novas produções, entre as quais, o vídeo. Antes, porém, de partir propriamente ao delineamento desse circuito imagético, faz-se necessária uma prévia contextualização do que se entende aqui por rede xinguana e de que forma os povos dessa região se configuram contemporaneamente.

\section{A Rede Regional Xinguana e sua Tessitura}

A área hoje denominada Território Indígena do Xingu é conformada por quatro terras indígenas contíguas: Terra Indígena do Xingu, Batovi, Wawi e Pequizal do Naruvôto. Juntas, elas abrangem mais de 26 mil km² que se estendem pela bacia do Rio Xingu, região nordeste do estado do Mato Grosso. Além de figurar como importante reserva de biodiversidade - preservando fauna e flora características da faixa de transição do cerrado do planalto central para as matas

2 Elementos que, na literatura etnológica, tipicamente caracterizam os povos do Alto Xingu enquanto componentes de um "sistema regional".

3 Cada etnia alto-xinguana é reconhecida por uma certa especialidade produtiva, entre as quais podemos destacar as panelas de cerâmica Wauja, os colares de caramujo dos povos Karib (Kalapalo, Kuikuro, Matipu e Nahukuá), e o sal de aguapé Aweti. Cf. a seção “Inimigos que trocam” (GUERREIRO, 2015: 406-415). 
sul-amazônicas -, esta área é também reconhecida pela diversidade cultural e linguística compreendida pelos dezesseis povos indígenas que hoje a habitam ${ }^{4}$. É em consideração a tal pluralidade que os povos que ocupam as distintas regiões desse Território (comumente designadas por Alto, Médio e Baixo Xingu) dificilmente são tratados em conjunto pela etnologia ${ }^{5}$, à exceção daqueles que integram o chamado complexo alto-xinguano ${ }^{6}$. Quanto a esse complexo, as diferentes etnias que o compõem costumam ser pensadas "em bloco" pela literatura especializada, uma vez que "se definem em grande medida pela criação de uma certa noção de 'interioridade" marcada por trocas institucionalizadas de vários tipos (e com graus diversos de competitividade e violência), em contraste com um (sempre relativo e móvel) 'exterior'” (Apresentação, neste volume).

O Alto Xingu, junto a outros conjuntos multiétnicos e multilíngues, tem sido motor de um debate - no qual se insere o presente dossiê - acerca de quais ferramentas analíticas seriam as mais produtivas para tratar dessas formações sociopolíticas compósitas sem correr o risco de essencializá-las nem dissolver suas singularidades. Nesse sentido, conceitos como "sistemas regionais", "sociedades multiétnicas" e "comunidades morais" tem sido mobilizados por diferentes autores. Em meio a esta miríade de conceitos, os autores desse dossiê propõem uma releitura da categoria de "conjuntos multicomunitários" de modo a "colocar em foco as formas da troca pelas quais unidades políticas maiores podem ser produzidas para a ação política e mantidas em 'estado de latência', sem que isso implique na emergência de qualquer forma de centralização" (Apresentação, neste volume).

O tema da produção e circulação imagética no Xingu parece iluminar tal questão, não de forma direta - no sentido de contribuir para melhor circunscrever conceitualmente o Alto Xingu - , mas indiretamente - evidenciando a qualidade porosa e plástica de suas fronteiras. Na medida em que se constitui contemporaneamente um circuito imagético que conecta povos do Alto, Médio e Baixo Xingu, sugiro falarmos, desde esta perspectiva, na conformação de uma rede regional ${ }^{8}$

4 Entre os povos habitantes do TIX, falam-se línguas das famílias Tupi-Guarani (povos Kamayurá e Kayabi); Juruna (povo Yudjá); Aweti (povo Aweti); Aruak (povos Mehinako, Wauja e Yawalapíti); Karib (povos Ikpeng, Kalapalo, Kuikuro, Matipu, Nahukuá e Naruvoto); Jê (povos Kisêdje e Tapayuna); e a língua isolada Trumai (povo Trumai).

$5 \quad$ Vale mencionar que além da referida heterogeneidade cultural e linguística, parte da dificuldade de tratar destes povos em conjunto diz respeito também às variadas histórias de ocupação do território, que abrangem desde os mais antigos ocupantes de provável origem Aruak, cujos primeiros indícios na região de que dispomos remontam ao século IX (HECKENBERGER apud FAUSTO, 2005: 16), a povos vindos de outras regiões que foram transferidos ao Xingu na década de 1960 a partir da atuação indigenista dos irmãos Villas-Boas.

6 O complexo alto-xinguano é composto pelos povos: Aweti, Kalapalo, Kamaiurá, Kuikuro, Matipu, Mehinako, Nahukuá, Naruvoto, Trumai, Wauja e Yawalapiti.

$7 \quad$ Tornar-se xinguano: "implica em aceitar um pacote cultural muito bem definido que inclui: um conjunto de valores éticos e estéticos; o aprendizado de disposições corporais e comportamentais; a adoção de uma alimentação que exclui carne de animais de pêlo; além da participação intensa em um universo mítico-ritual, que torna públicas as relações hierárquicas entre chefes e não-chefes, ao mesmo tempo em que expõe, na forma de uma competição regrada, a simetria entre os vários grupos locais" (FAUSTO, 2005: 22). 


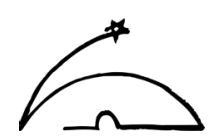

xinguana que transpõe fronteiras tipicamente vigentes nos estudos em etnologia. Assim, enquanto a categoria de "conjunto multicomunitário" se apresenta como uma possibilidade potencialmente prolífica para colocar em relação diferentes formações sociopolíticas de uma paisagem amazônica mais ampla - tais como as do Alto Xingu, do Alto Rio Negro, contextos Timbira e Guarani - , sugiro mobilizar aqui a noção mais capilar de rede para colocar em relação os povos do Alto, Médio e Baixo Xingu.

Pensar o Xingu enquanto rede nos aproxima de esforços, já empreendidos no campo da etnologia, que caminharam no sentido de sublinhar o caráter fluído e aberto das unidades sociológicas e o princípio - comum a diversos povos ameríndios - de que a "mistura" é essencial à vida social. Com o olhar voltado para as redes de intercâmbio multilocalizadas na região das Guianas, Gallois (2005: 13) fala da "impossibilidade de se delimitar totalidades, pois separar o "interno" e o "externo" seria uma tarefa impossível, senão enganosa". Na medida em que se abre mão de estabelecer e operar com recortes étnicos ou geográficos, a noção de fronteira emerge, não como "limite ou muralha", mas como espaço "de conjunção, de intersecção ou de transição em que se realizam as interações" configurando-se, assim, em "espaço propício à construção de novas formações e representações sociais" (GALLOIS, 2005: 9). Distanciando-se, então, de abordagens que acentuavam contextos marcados pelas noções de separação e resistência, os estudos orientados por Gallois buscaram "incorporar situações em que a negociação, a troca e a fusão predominam em relação à confrontação" (GALLOIS, 2005: 9). Conforme explica a autora, tal caracterização etnográfica apoiou-se na noção de rede mobilizada por Latour (1994), uma vez que esta "permite apreender espaços de mediação e de tradução entre esferas normalmente tomadas como separadas" (GALLOIS, 2005: 15).

Afinada com tais premissas, pretende-se aqui navegar pela rede xinguana de modo a iluminar, não as unidades ${ }^{9}$ que a compõem, mas as maneiras como estas se conectam, comunicam, trocam e misturam, sobretudo, através do vídeo. Nesse sentido - se os povos do Médio e Baixo Xingu costumam ser tratados pela etnologia em suas singularidades, e os do Alto Xingu como componentes de um sistema -, o que proponho é uma espécie de perspectiva transversal, que permita a transposição daquilo que, sob outra perspectiva, poderia figurar como barreira analítica. Analogamente ao que os organizadores deste dossiê apresentam para a ideia de "conjunto multicomunitário", sugiro pensar a noção de rede xinguana como "um conceito que não parece definir um objeto, mas um tipo de movimento, ou, melhor, movimentos transitórios/movimentos

9 Quanto à delimitação das “unidades" que compõem o complexo alto-xinguano, Guerreiro (2016: 25) observa: "Com a retomada do crescimento populacional após as epidemias de gripe e sarampo, principalmente a partir da década de 1970, mais aldeias começaram a ser criadas. Com isso, nomes de coletivos têm se multiplicado, e nomes de grupos tidos como desaparecidos voltam a ser ouvidos. Os Kalapalo, com quem tenho trabalhado, podem deixar o interlocutor confuso quando dizem que uma de "suas" aldeias seria, "na verdade mesmo", Jagamü, enquanto outra seria Uagihütü, outra Lahatua. O que pode estar em jogo no uso alternativo desses nomes? De fato, essa situação levanta a questão de saber quais são as "unidades" que compõem o complexo regional xinguano, quais são suas escalas, e quais os sentidos e efeitos da etnonímia em sua própria constituição. Os nomes de coletivos parecem apontar para a insuficiência do termo "unidade", pois sua potencial proliferação revela que tais unidades, caso existam, são sempre múltiplas e podem apresentar visões alternativas de si mesmas". 
em estado perpétuo/contínuo de transição: a expansão, a contração e a segmentação de redes de trocas" (Apresentação, neste volume).

Tal abordagem supõe o reconhecimento de que os diferentes povos que integram o TIX estão cada vez mais conectados por relações que vêm se intensificando à medida que uma nova conjuntura se apresenta. Em sua configuração contemporânea, somos defrontados com um complexo xinguano cada vez mais intrincado, em que o universo antes distante dos Kawaiweté se faz cada dia mais presente para os alto-xinguanos, assim como o universo ritual destes penetra lentamente em muitos grupos a jusante do Rio Xingu. Desde uma perspectiva política, isso tem se manifestando nas últimas décadas através da constituição e do fortalecimento de organizações políticas interétnicas, tais como a Associação Terra Indígena do Xingu (ATIX), fundada em 1995, e a Associação Yamurikumã das Mulheres Xinguanas, que atua desde 2009. Tais associações assumem uma identidade pan-xinguana que abarca todas as etnias do TIX - identidade eficaz na medida em que o compartilhamento de um mesmo território estimula a convergência de interesses entre esses povos. Desde uma perspectiva ritual, podemos citar a progressiva participação de povos dos Médio e Baixo Xingu em festas ${ }^{10}$ tipicamente alto-xinguanas. Na minha própria experiência no Alto Xingu durante a realização do Quarup, presenciei um pequeno grupo Ikpeng ${ }^{11}$ que assistia ao ritual pela primeira vez. Neste mesmo Quarup, estendi minha rede ao lado de um grupo de indígenas Kisêdjê $\hat{e}^{12}$ que, embora participassem da festa como os demais alto-xinguanos, hospedavam-se na casa reservada aos brancos e índios "não-xinguanos" e guardavam elementos distintivos em sua pintura corporal. Desde uma perspectiva estética, podemos mencionar a apropriação de elementos visuais da cultura alto-xinguana por outros povos do TIX. Na minha vivência entre mulheres Ikpeng, pude observar como elas pintam sobre seus corpos, em uma mesma ocasião, grafismos considerados propriamente Ikpeng, bem como aqueles que elas reconhecem ser alto-xinguanos. Elas também adotaram do Alto Xingu os volumosos colares de miçangas de uma única cor, mas os vestem de modo distinto: ao invés de dependurá-los no pescoço como fazem as alto-xinguanas, as Ikpeng os trazem em uma disposição cruzada, atravessando o peito e as costas.

Em consideração à complexidade desse arranjo, sugiro tomarmos as noções de Xingu e de xinguanidade como categorias flexíveis, cujas dimensões e limites variam conforme a perspectiva mobilizada ${ }^{13}$. Quando me refiro, então, à rede regional xinguana - ou a categorias que variem a partir dela, como "circuito imagético xinguano" - tenho em mente indígenas pertencentes a povos heterogêneos que não necessariamente partilham de um mesmo universo cultural, mas

10 O termo festa é comumente empregado pelos xinguanos como uma forma genérica de se referir a um variado conjunto de rituais realizados entre estes povos.

11 Os Ikpeng historicamente guerreavam com os povos alto-xinguanos até serem, na década de 1960, transferidos ao então Parque Indígena do Xingu, momento em que se encontravam já bastante reduzidos e debilitados em função das consequências do contato com os não-indígenas.

12 Os Kisêdjê adotaram extensivamente traços alto-xinguanos, mas mantêm simultaneamente elementos da cultura Jê.

13 Quanto a esta discussão, cf. Menezes Bastos (1994), onde o autor distingue as sociedades xinguana, xinguense e xinguara. 


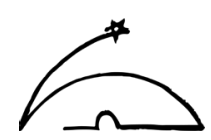

que, a despeito de suas diferenças, se encontram, ora mais, ora menos, conectados. Sendo assim, se a noção de rede regional xinguana é uma ficção, em qualquer escala que seja tomada - uma vez que suas fronteiras se produzem e se dissolvem em resposta a determinadas circunstâncias e, também, à medida que o nosso olhar transita por distintos objetos e escalas de observação -, ela não deixa de ter um valor heurístico, e é nesse sentido que ela deve ser aqui entendida.

Seguindo então esta abordagem, a pesquisa a partir da qual se desenvolve o presente ensaio transitou por diferentes aldeias, povos e regiões do TIX identificando os elementos que os aproximam e distinguem, mas dando especial atenção ao lugar da produção audiovisual em sua configuração enquanto rede. Manter minha atenção voltada às dinâmicas de produção e circulação imagética entre os povos do Xingu acabou me levando a percorrer esta (sinuosa) trajetória etnográfica que, por sua vez, reproduzia um movimento impulsionado pelo próprio objeto ao qual eu me atentava. No contexto dessa pesquisa, a circulação pelo TIX se deu, então, não como a priori metodológico, mas como resultado da qualidade viajante das próprias imagens.

\section{Notas para o Delineamento de um Circuito Imagético Xinguano}

Falar de "cinema indígena" (ou "mídia indígena"14) no Brasil - país que tem alimentado empiricamente esse campo desde meados da década de $1980^{15}$ - significa se debruçar sobre uma abundante literatura que se constitui na interface dos campos da antropologia, do cinema e da comunicação. Em meio a esses trabalhos, desenvolvem-se interessantes reflexões que apontam para as formas como os regimes sócio-cosmológicos e os universos estético-visuais ameríndios se expressam através da linguagem audiovisua ${ }^{16}$. A produção do chamado "cinema indígena" cuja definição e limites seguem sendo debatidos - nasce no país por meio da atuação de alguns antropólogos e documentaristas ligados ao projeto indigenista corrente nas décadas de 80 e 90 . A continuidade e o amplo desenvolvimento desta produção cinematográfica se devem, em grande parte, às inciativas precursoras de formação audiovisual entre as quais destaca-se o trabalho desenvolvido pela ONG Vídeo nas Aldeias (VNA), cuja atuação envolveu também comunidades no Xingu ${ }^{17}$.

Conforme argumento em minha dissertação (SERBER, 2018), hoje, as sementes plantadas

\footnotetext{
14 Ambas as categorias são bastante permeáveis e, portanto, dificilmente podem ser definidas com precisão. O termo "mídia indígena", porém, aponta para a inclusão de uma maior gama de linguagens e tecnologias e dá lugar à mistura entre os domínios do cinema e da comunicação. Enquanto o termo "cinema indígena" tem se sobressaído no debate sobre o tema em âmbito nacional, o termo "mídia indígena" tem sido amplamente empregado em festivais de cinema internacionais e por autores que lidam com este fenômeno desde uma perspectiva global. A presente pesquisa - que se constitui sobre a interface entre o cinema e a comunicação e dialoga com autores que apresentam distintas abordagens sobre o tema - mobilizará ambos os conceitos ao longo de seu desenvolvimento. 2015; GOW, 1995.
}

17 Particularmente entre os Kuikuro e os Ikpeng. 
por este projeto inaugural brotam entre diferentes povos, habitantes das mais diversas regiões do país, e assumem as mais variadas formas - ora mais próximas, ora mais distanciadas do "modelo fílmico" proposto pelo VNA. Em outras palavras, a produção audiovisual indígena, antes dependente dos recursos e da atuação de organizações externas às comunidades, hoje "transborda": vem encontrando seus próprios modos de capacitação e produção, vem assumindo sua própria linguagem e forma estética e, também, criando seus próprios meios de circulação e recepção. Esse pulsante processo de transformação nos modos de produção e circulação imagética entre os povos indígenas pode ser observado, entre outros cenários possíveis, no Território Indígena do Xingu. Porém, uma série de fatores - a intensa e complexa relação dos povos xinguanos com o mundo não-indígena e a considerável atenção e recursos que estes recebem de diversas organizações (em contraste com povos de outras regiões) - faz dessa região um espaço privilegiado para a observação do fenômeno em questão.

A minha trajetória etnográfica compreendeu, como já mencionado, uma sinuosa incursão por entre diferentes regiões, povos e aldeias do Xingu. Mas compreendeu também uma incursão por variadas formas de fazer, pensar, ver e circular as produções audiovisuais, formas que, em minha dissertação, distingui como constitutivas de diferentes "regimes imagéticos" (SERBER, 2018: 16). O primeiro deles seria aquele que representa a continuidade de um modelo de produção audiovisual indígena inaugurado no Brasil ao final da década de 80 - que está orientado pelo formato "oficina" de formação, depende da iniciativa e dos recursos de organizações externas às próprias comunidades e é marcado pela intensa colaboração entre indígenas e não-indígenas. Desse regime resultam muitas das produções que, no Brasil, compõem o que convencionou-se chamar de "cinema indígena" e que, sob este rótulo, circulam por audiências nacionais e internacionais, particularmente por festivais de cinema documentário e/ou etnográfico. O segundo seria um regime mais autônomo e espontâneo de produção videográfica que resulta da iniciativa e da gestão dos próprios indígenas e cuja produção é rapidamente colocada em circulação e consumida pelo público local. Os vídeos resultantes deste regime mais difuso, diferentemente do primeiro, dificilmente alcançam os circuitos não-indígenas de cinema e costumam escapar às análises da literatura especializada.

Quando me refiro à constituição de um circuito imagético que atravessa e conecta a rede regional xinguana, tenho em mente particularmente esse segundo regime imagético, no qual focarei nas próximas páginas. Sem pretender retraçar todos os meandros de minha trajetória pelo Xingu, destacarei a seguir apenas algumas de suas passagens que, sugiro, nos ajudam a caracterizar aspectos importantes do circuito imagético em questão. 

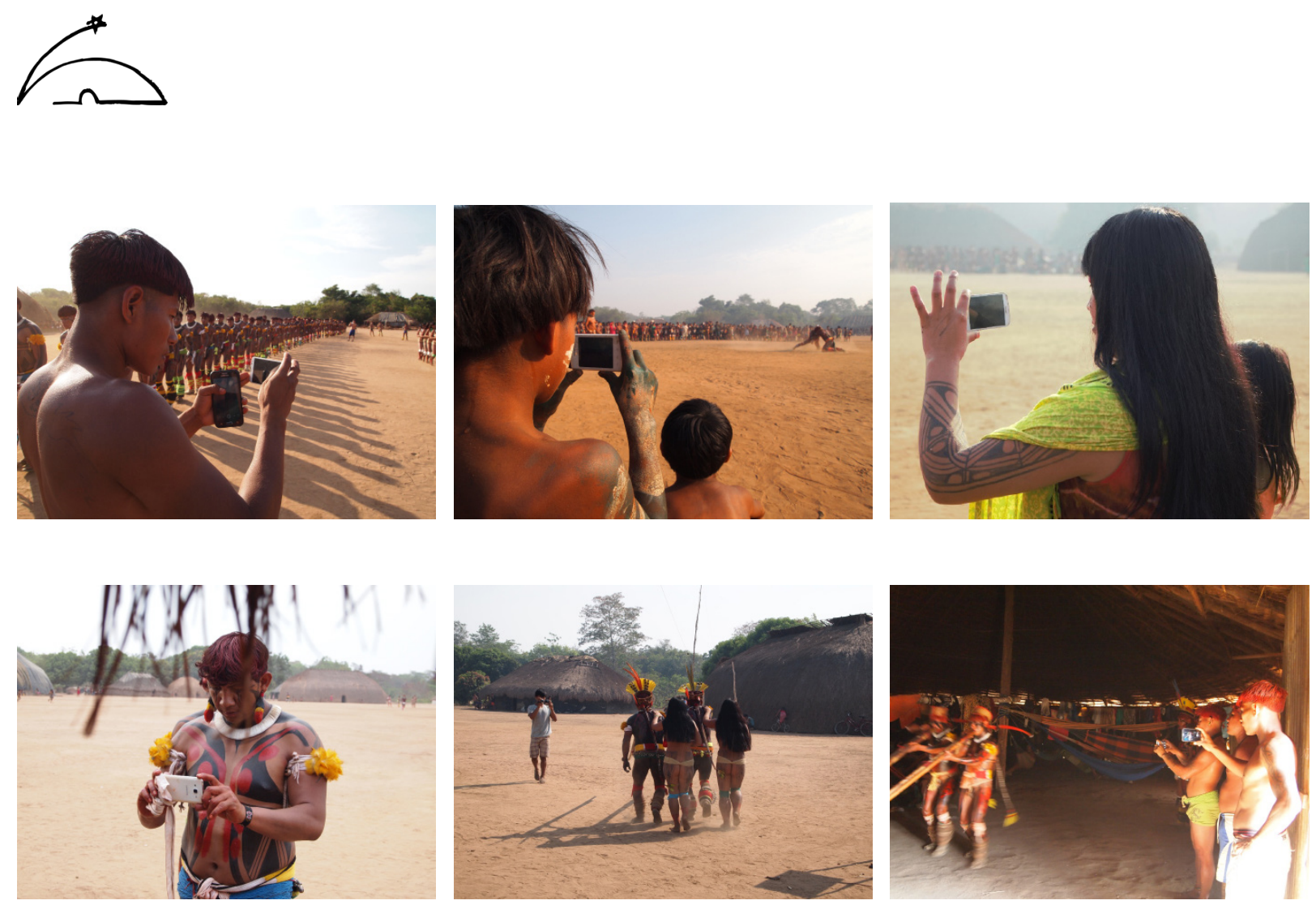

Hoje, basta uma rápida incursão pelas distintas regiões do Xingu para notar como a produção videográfica - particularmente por meio de mídias móveis, como os smartphones - permeia significativamente a vida cotidiana das aldeias. São continuamente, e abundantemente, produzidos registros fotográficos e fílmicos efêmeros de atividades corriqueiras - selfies, jogos de futebol, pescarias, confecção de colares, treinos de huka-huka $a^{18}$ cuja circulação costuma ser mais restrita e em geral nunca extrapolando o próprio suporte no qual foram produzidos, mantendo-se circunscritos pelas telas dos smartphones. Menos efêmeros, mas igualmente frequentes, são os registros de uma série de outras atividades que compõem a vida xinguana contemporânea - tais como encontros de lideranças, reuniões de governança interna ao TIX, reuniões com representantes da política local, reuniões com profissionais indígenas e não-indígenas nas áreas da saúde e da educação - cuja circulação é mais ampla, viajando, na ausência de internet, por conexões bluetooth pelas muitas aldeias dos povos da região. Tais "modalidades" de produção e difusão podem ser observadas no Xingu nos mais diversos arranjos e combinações.

Embora seja evidente nesse contexto a observação de um fenômeno generalizado de democratização das tecnologias audiovisuais - tanto no sentido de tornarem-se acessíveis a mais pessoas, mas, também, no sentido de ampliar substancialmente a gama de objetos filmáveis: filma-se quase tudo - pude observar ao longo de minha trajetória como, no Xingu, o ritual configura um momento privilegiado de produção imagética, apontando, assim, para uma intrincada relação entre a produção de vídeos e a produção ritual, tema ao qual retornarei mais adiante.

Indícios da predominância dos vídeos de rituais no circuito imagético xinguano se apresentaram logo em minha primeira entrada no TIX, na qual estive acompanhando uma oficina de

18 Luta corporal alto-xinguana na qual se enfrentam "representantes" de diferentes povos. 
formação audiovisual oferecida pelo Instituto Catitu, sob coordenação de Mari Corrêa ${ }^{19}$, a mulheres Ikpeng e Kawaiweté do Médio e Baixo Xingu (situação que constitui parte do primeiro "regime imagético" a qual me referi). Embora a oficina transcorresse em torno da capacitação no manejo de câmeras profissionais de filmagem e programas de edição, eu notava um incessante fluxo de vídeos que atravessavam a oficina através dos smartphones das jovens alunas. Entre os vídeos que elas baixavam em eventuais acessos à conexão wi-fi do Polo Pavuru ou trocavam por meio de conexão bluetooth, os registros de rituais realizados recentemente em seu próprio povo, bem como em outros povos do Xingu - particularmente os grandes rituais alto-xinguanos - mostravam-se os mais recorrentes. Movida por tal observação preliminar, pareceu-me potencialmente produtivo - no sentido de melhor compreender as "dinâmicas da imagem" no universo xinguano - seguir em minha próxima viagem à região do Alto Xingu para então acompanhar a realização do Quarup, o emblemático ritual funerário da nobreza alto-xinguana. Esta, sendo a mais célebre das festas do Território, acabou revelando-se, como tal, uma espécie de epicentro, ou ponto máximo, da produção e circulação imagética do Xingu.

Naquele ano ${ }^{20}$, o Quarup seria realizado em aldeias dos povos Wauja, Yawalapití e Nahukuá, entre as quais pude comparecer às duas últimas com o intuito de observar, tanto a maneira como os xinguanos têm gerido imagens de seus rituais captadas por não-indígenas, quanto os circuitos imagéticos que eles próprios vem tecendo por meio da produção e circulação de vídeos em contextos cerimoniais. Entre os sete alto-xinguanos "homenageados" na aldeia Tuatuari, do povo Yawalapití, estava Pirakumã Yawalapití, grande liderança dos povos do Xingu que ficou amplamente conhecido por sua habilidade diplomática e atuação política. Dada a notoriedade de Pirakumã (o "embaixador do Xingu"), o ritual ganhou contornos de megaevento, atraindo para a aldeia, não apenas representantes de todos os povos do Alto Xingu e indígenas de dentro e fora do TIX, mas também mais de duzentos caraíba ${ }^{21}$. Tal configuração "inflacionada" do Quarup é emblemática da forma que este ritual assumiu desde a intensificação do contato com a sociedade brasileira, passando a tomar "novas proporções, que talvez nunca tenha tido antes do contato" (GUERREIRO, 2015: 47)22.

A heterogênea composição de convidados do Quarup deu lugar a um mosaico de variadas formas de registro da série de acontecimentos que compõem o ritual. Neste cenário, atuavam

19 Mari Corrêa formou-se em 1987 em direção de documentários na escola francesa de cinema Ateliers Varan, escola fundada por Jean Rouch e guiada pelos princípios do "cinema direto". A partir de 1992, Corrêa começou a trabalhar no Parque Indígena do Xingu, o que resultou em seu primeiro filme, O Corpo e os Espíritos (1996). A partir de 1998, Corrêa passou a trabalhar junto ao Vídeo nas Aldeias (VNA), projeto precursor na formação de cineastas indígenas no Brasil. Depois de atuar durante dez anos como co-diretora do VNA, ela fundou o Instituto Catitu, onde continua produzindo documentários com a temática indígena e direciona as atividades de formação, particularmente, às mulheres indígenas. Entre suas principais produções estão Voix Indienne (1997); Pirinop - Meu Primeiro Contato (2006); Para Onde forma as Andorinhas? (2015); e Quentura (2018).

20 Realizei todas as minhas viagens de campo ao Xingu ao longo de 2016.

21 Expressão pan-xinguana para se referir aos não-indígenas.

22 Sobre esta configuração "inflacionada” do Quarup e a ampla presença de convidados brancos, cf. a seção ““Aqui está parecendo um aeroporto’: Os brancos nos rituais” (GUERREIRO, 2015: 415-431). 


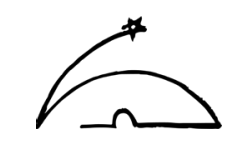

indígenas e caraíbas, alto-xinguanos e índios $\operatorname{bravos}^{23}$, cinegrafistas e fotógrafos profissionais e amadores. Empregavam-se equipamentos de filmagem profissionais, drones, câmeras amadoras e smartphones, dos quais resultaram reportagens de jornal ${ }^{24}$, postagens em redes sociais, vídeos que viriam a circular internamente pelas aldeias, bem como em redes mais amplas por meio de sua disponibilização na internet.

Em meio a essa paisagem midiática difusa, fui pouco a pouco mapeando os distintos "gêneros" de produção audiovisual que ali se desenrolavam. Alguns convidados não-indígenas encarregavam-se dos registros "oficiais" da festa, isto é, aqueles previamente acordados com as famílias anfitriãs (“donos da festa”, no jargão xinguano) e firmados em contratos elaborados em parceria com a FUNAI. Observava-se também ali um amplo e pulsante cenário de indígenas munidos da mais diversa parafernália de fotografia e filmagem. Em suas mãos abundavam desde simples aparelhos celulares e tablets a equipamentos profissionais de audiovisual. Tal equipe "paralela" (ao menos desde a perspectiva dos não-indígenas e dos anfitriões xinguanos que haviam estabelecido acordos com equipes profissionais de filmagem) fazia registros semelhantes às câmeras dos não-indígenas. Todos os equipamentos estavam, grosso modo, ligados nos mesmos momentos. No entanto, me parecia que eram orientados por objetivos bastante distintos: enquanto os não-indígenas buscavam uma imagem genérica do Quarup - um pot-pourri de cenas que de alguma maneira sintetizassem esteticamente aquela experiência -, os indígenas buscavam um registro muito mais específico e sistemático - buscava-se filmar uma certa luta de huka-huka de um parente próximo ou buscava-se filmar todas as lutas de huka-huka para que aquele vídeo pudesse posteriormente circular pelas aldeias, possibilitando avaliações mais detidas sobre a performance de cada indivíduo. Entre os indígenas que realizavam estes registros, era notável a predominância masculina. Em meio às dezenas de câmeras, presenciei apenas uma sendo manuseada por uma mulher xinguana: era a câmera de filmagem da Mawó (Casa de Cultura Ikpeng) nas mãos de uma jovem participante da oficina de audiovisual oferecida pelo Instituto Catitu, à qual me referi no início deste relato.

Passados alguns dias na aldeia Tuatuari, me dirigi à aldeia Aiha, do povo Kalapalo, onde fiquei hospedada durante o período que separava a realização do Quarup Yawalapití do Nahukuá, o último a ser realizado no ano. Em Aiha fui generosamente acolhida por uma família que me permitiu experimentar o cotidiano alto-xinguano para além da agitada dinâmica gerada pela atividade ritual. Conversando com um dos homens desta família sobre a produção audiovisual entre os Kalapalo de Aiha, ele me contou que costuma filmar as festas e exibir seus vídeos na aldeia em estado "bruto", queixando-se de não dominar o processo de edição. Aproveitando a minha presença na aldeia, ele me pediu, então, que o ensinasse e o ajudasse a editar um vídeo filmado

23 Termo comumente empregado pelos alto-xinguanos para se referir a povos indígenas que não pertencem a seu próprio sistema cultural, o qual se distingue por seu caráter pacífico e diplomático.

24 Disponíveis em: $<$ https://www.cartacapital.com.br/sociedade/sete-tristes-troncos-diplomacia-e-um-protesto/> $\mathrm{e}<$ https://www1.folha.uol.com.br/paywall/signup.shtml?http://arte.folha.uol.com.br/poder/2016/08/27/xingu/>. Acesso em 15/03/2020. 
por ele do uluki do povo Kuikuro realizado na aldeia Kalapalo.

Numa tarde, levamos à cozinh $a^{25}$ uma carteira escolar onde acomodamos seu laptop conectado por um longo cabo no gerador a gasolina. Ele então me mostrou uma extensa lista de arquivos a partir da qual eu pedi que selecionasse os que comporiam o filme, para que estes fossem em seguida importados ao programa de edição. Sugeri que essa seleção fosse feita no próprio computador, mas ele rapidamente optou por anotar os nomes dos arquivos selecionados numa folha de papel. Os vídeos eram muitos e me pareceu mais apropriado deixá-lo à vontade nesse momento de seleção. Pedi, então, que me chamasse depois de concluída esta etapa. Passadas algumas horas, ele me apresentou uma lista, ainda bastante longa, de arquivos selecionados. Uma vez importados para o programa de edição, verifiquei que ainda havia mais de quatro horas de filmagens. Perguntei a ele qual era a ideia do filme: O que deveria ser mostrado? Para quem seria exibido? Quanto tempo de duração deveria ter? Vendo pouco sentido nas minhas perguntas, ele dizia apenas que era para mostrar para as crianças e para exibir em outras aldeias. A ideia de estabelecer previamente uma duração ao filme, para orientar o processo de edição, não pareceu a ele muito apropriado. Segundo ele me relatou, não tinha problema o vídeo ser muito longo, aliás, era até melhor, pois quando os vídeos são curtos as pessoas pedem para assistir de novo. Passamos então a mexer nas ferramentas mais básicas do programa: corte e supressão de clipes, efeitos de transição, texto de abertura e créditos. Pouco a pouco o vídeo foi tomando forma e ele, visivelmente cansado da atividade, ansiava por sua finalização. Terminamos com um vídeo de $2 \mathrm{~h} 42 \mathrm{~min}$ que foi exibido na casa na noite seguinte.

Transcorrido esse período de "pausa" entre a realização dos dois Quarup, cheguei à aldeia do povo Nahukuá, o mais diminuto dos grupos que integram o complexo alto-xinguano. O Quarup que ali se realizaria distinguia-se bastante daquele que eu havia presenciado na aldeia Yawalapití. Primeiramente, sua dimensão era muito menor: a aldeia em si era menor e participavam do ritual exclusivamente povos alto-xinguanos que traziam, com relação ao evento anterior, menos representantes. Havia pouquíssimos não-indígenas presentes, entre os quais estava um pequeno grupo de turistas - composto por europeus, norte-americanos e paulistanos -, levados à aldeia por uma agência de turismo pertencente a uma mulher Kalapalo. Uma das ocasiões em que me aproximei deste grupo se deu quando fui chamada por um alto-xinguano para auxiliar na tradução de seu pedido aos estrangeiros: ele perguntava aos visitantes se estes poderiam dar a ele um cartão de memória, uma vez que ele tinha uma câmera, mas tinha se esquecido de descarregar os arquivos do cartão. Um dos estrangeiros prontamente respondeu que isso não era possível, pois o modelo de seus cartões de memória era incompatível com a câmera do alto-xinguano (ainda que ele não tivesse propriamente verificado isso). Não querendo, no entanto, encerrar a conversa com essa negativa, o turista ofereceu enviar depois por e-mail as fotografias que ele próprio tiraria durante a festa. Foi então a vez do alto-xinguano responder negativamente, pois ele não tinha interesse

$25 \quad$ Pequena estrutura de madeira e cobertura de palha que se localiza atrás de cada casa (fora do círculo da aldeia). Ali o grupo doméstico se reúne para preparar e produzir alimentos (processar a mandioca para produzir polvilho, moquear peixes, etc.), além de ser um local de intensa socialidade íntima, familiar. 


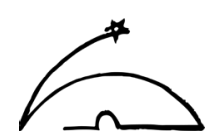

nas imagens que aquele estrangeiro iria produzir. Em seguida, ele me explicou a razão desse desinteresse: aquele turista certamente não filmaria a festa "do jeito indígena", não vai querer filmar tudo, não sabe as diferenças entre os cantos e as danças.

A partir destes fragmentos de minha experiência no Xingu podemos começar a delinear alguns aspectos importantes do circuito imagético que se tece entre os povos da região. Esse relato permite, em primeiro lugar, esboçar algumas ideias acerca do contraste que existe entre o "jeito indígena" e o "jeito não-indígena" de produzir filmes, bem como o modo de editá-los (ou a escolha por não fazê-lo). Depois, nos possibilita pensar sobre a maneira como a posterior circulação desses vídeos introduz uma nova forma de apreciação do ritual, cuja lógica possivelmente esteja relacionada às dinâmicas locais de competição. Por fim, tais passagens nos oferecem subsídios para refletir sobre o motivo pelo qual, a despeito da significativa diversificação de temas de registro audiovisual, o ritual segue configurando um momento privilegiado de produção e circulação imagética.

Não por acaso, presumo, tais questões são também norteadoras do esforço reflexivo presente em outra investigação desenvolvida contemporaneamente a essa. Refiro-me aqui ao trabalho dos pesquisadores André Demarchi e Diego Madi Dias (2018), cujas reflexões conjuntas em torno da produção audiovisual Mebêngôkre ressoam significativamente as observações que partem de minha experiência no Xingu. Em consideração a tais ressonâncias, mobilizo a seguir algumas considerações destes autores entre os Mebêngôkre de modo que possam dialogar com - e potencialmente iluminar - o universo xinguano no que diz respeito à constituição de um circuito imagético que lhe é próprio.

Quanto ao contraste entre o "jeito indígena" e o "jeito não-indígena" de filmar os rituais, isso se expressa, em primeiro lugar, no que diz respeito à seleção do "conteúdo" filmado. A incapacidade dos brancos (ou, ao contrário, à capacidade dos xinguanos) de situarem as músicas (e, logo, as danças) nos conjuntos dos quais elas são parte - e dos quais, portanto, depende cada execução particular - aparece como fator determinante nessa distinção. Enquanto eu observava entre os não-indígenas uma busca por registrar fragmentos do Quarup que, agregados, resultassem em uma imagem genérica e sintética do ritual, os indígenas apontavam suas câmeras de forma muito mais consciente e sistemática. Era predominante entre os xinguanos um interesse por "filmar tudo", sugerindo que "festa boa é festa inteira", não havendo, ali, lugar para fragmentações. A existência de um jeito propriamente "indígena" de filmar também se evidencia no relato apresentado por meio da recusa do alto-xinguano pelas imagens produzidas pelo visitante estrangeiro no Quarup Nahukuá, imagens que certamente não atenderiam aos requisitos de um registro ritual "adequado".

Em artigo sobre os circuitos imagéticos entre os mebêngôkre, Demarchi e Madi (2018) dão início às suas reflexões a partir da fala de Bepunu Kayapó, que diz: “meu sonho é filmar todas as 
festas, toda atividade e todo processo de cada festa" - fala que aponta também para a importância da sequencialidade, continuidade e inteireza dessas filmagens. Segundo estes autores,

\begin{abstract}
Aqui, as características técnicas do produto audiovisual são condicionadas pelo tema e pela imposição da audiência nativa. "Nós gostamos de ver a festa inteira", dizem os Mebêngôkre aos cinegrafistas que experimentam as técnicas de edição. Estes, por sua vez, concordam. Sonham em filmar "todas as festas [...] todo processo de cada festa". Filmar todo processo quer dizer filmar toda a antecena ritual: as caçadas e pescarias na floresta em busca de alimento; a preparação dos adornos a serem usados nas festas; a produção da pintura corporal que os diferentes grupos etários masculinos e femininos utilizarão, os ensaios das canções e passos de dança que serão performados durante o ritual. Além, é claro, da própria cerimônia em si, que pode ter a duração de vários dias (DEMARCHI, MADI, 2018: 44-45).
\end{abstract}

Embora em minha experiência no Xingu eu não tenha presenciado diretamente esse registro "integral" - que capte toda a antecena ritual - do Quarup, esse se manifestava como um desejo das famílias anfitriãs. Muitas vezes me foi explicado que aquilo que nós caraíba chamamos de Quarup é, na realidade, apenas a fase final, o ápice, de uma longa e complexa sequência de atividades que se estende ao longo de todo o ano. A filmagem deste "ciclo completo" aparecia nesses contextos como algo almejado e ainda a ser produzido pelos cineastas locais. Se "festa boa é festa inteira", assim, talvez, a lógica que ali opera não seja da "lembrança" (como fazemos com nossos vídeos caseiros de aniversários), mas algo mais próximo a uma re-experimentação (é preciso ouvir tudo, ver todas as lutas etc.). Enquanto o registro que objetiva a lembrança exige apenas "pistas" ou "fragmentos" visuais e sonoros capazes de evocar uma experiência guardada na memória, o registro que visa a re-experimentação reivindica "totalidades" capazes de suscitar experiências sensoriais as mais próximas possíveis daquelas experimentadas durante a realização do ritual.

A longa duração e a sequencialidade destas filmagens diz respeito também à perspectiva xinguana acerca do processo de edição. Conforme aparece em meu relato, particularmente no tempo em que estive entre os Kalapalo, o acesso aos equipamentos, programas e conhecimentos técnicos necessários à edição de filmes revelam-se como recursos desejados por alguns dos produtores locais. No entanto, os objetivos da edição e o processo de fazê-lo em muitos aspectos se diferem daquilo que convencionalmente atribuímos a esse procedimento. Na experiência relatada, embora a edição suponha, inevitavelmente, uma seleção - e, portanto, um recorte - do material filmado, esta não prevê, de modo algum, uma intervenção sobre a ordem dos acontecimentos. $\mathrm{O}$ filme resultante, ainda que de duração mais curta que a soma de todas as filmagens do ritual, é, ainda, bastante longo para os parâmetros convencionais do cinema. Enquanto, neste contexto, reduzir o tempo do filme não aparece como objetivo central da edição, a introdução de elementos "pré" e "pós" filme (título de abertura, créditos finais e agradecimentos) mostram-se bastante significativos para os cineastas locais. 
Voltando ao caso mebengokrê, Demarchi e Madi apontam como um equívoco

compreender as "filmagens rituais" como uma possível prática do vídeo em "estágio rudimentar". Ao contrário, trata-se de uma escolha estética demandada pelo interesse da audiência em acompanhar sequencialmente os mínimos detalhes do ritual gravado, a ponto de não fazer sentido para eles a diferenciação clássica no ocidente entre "material bruto" e "produto acabado" (DEMARCHI, MADI, 2018: 44).

Quanto ao interesse pontual de alguns mebêngôkre pela edição, os autores sugerem, que este processo tem sido cada vez mais valorizado no âmbito dos "projetos" e que, portanto, a busca pelo seu aprendizado estaria associada a uma expectativa em corresponder às demandas externas: "Essas pessoas são participantes de 'projetos' e percebem a necessidade de um formato, entendendo que o vídeo editado corresponde melhor como 'produto' para a articulação em outras redes (no mundo dos kuben, principalmente)" (MADI, 2011: 73 apud DEMARCHI, MADI, 2018: 44) - hipótese que mereceria ser apreciada também em contexto xinguano.

É, no entanto, importante assinalar que se observam no Xingu, no âmbito da edição, experiências bastante heterogêneas no que diz respeito aos equipamentos e conhecimentos empregados: esta pode ser realizada em softwares profissionais, por aqueles que já passaram por alguma capacitação; em programas amadores, disponíveis na maioria dos laptops; e também nos próprios smartphones nos quais as imagens foram captadas, através do uso de aplicativos. Sobretudo nesse último caso, pude verificar a existência (ao que parece, cada vez mais comum) de vídeos de curta duração com expressivo uso dos recursos de edição (compondo cenas breves e recortadas, não sequenciais, e lançando mão da importação de áudios de outros contextos $)^{26}$ - distanciando-se, assim, do que Demarchi e Madi definem como "filmagens rituais" em contexto mebêngôkre e, também, daquilo que observei em minha passagem entre os Kalapalo.

Uma vez filmados e editados (ou não), os vídeos são rapidamente colocados em circulação para o acesso do público local. Aqueles que foram produzidos ao longo do Quarup eram visionados quase imediatamente nas telas dos smartphones. As versões mais longas e/ou editadas do ritual podiam ser assistidas algum tempo depois, por vezes em exibições coletivas nos televisores de dentro das casas, por vezes até mesmo em telões no centro da aldeia. Se, como vimos, a busca por "filmar tudo" aparece como resposta a um desejo pela reexperimentação, os momentos compartilhados de visionagem parecem indicar que essa busca pela totalidade seja ainda mais abrangente: não apenas assistem-se, repetidamente, as longas filmagens das festas, como também gostam de assistir na sequência (havendo combustível para tanto) filmagens das várias festas alto-xinguanas realizadas em época recente (o Quarup dos Kamayurá, depois dos Yawalapití, o Jawari dos Kalapalo etc.). Filmagens, por vezes muito semelhantes, de uma mesma festa, captadas por

26 Um exemplo deste tipo de produção disponível em: $<$ https://www.youtube.com/watch?v=fcsOkYu9t8c $>$. Acesso em: 15/03/2020. 
diferentes cinegrafistas, não são vistas como redundantes. Muito pelo contrário, são procuradas de casa em casa após um período de festas, convidando as pessoas a circularem junto às imagens.

Embora os trechos do relato apresentado estejam centrados em um contexto ritual alto-xinguano, a minha circulação, em outras ocasiões, por aldeias nas regiões do Médio e Baixo Xingu me permitiu observar que os vídeos produzidos nesse contexto alcançam também esses outros setores do TIX. Os demais povos do Território - Ikpeng, Kawaiweté, Kisêdje, Tapayuna e Yudjá - não apenas assistem às filmagens dos rituais alto-xinguanos, mas se integram a este circuito, também, na condição de "produtores de conteúdo", uma vez que imagens de seus rituais, reciprocamente, penetram as telas alto-xinguanas. Neste sentido, talvez seja possível estabelecer um paralelo entre a dinâmica de circulação de vídeos e o - ambíguo e nunca completamente terminado - processo de "xinguanização" dos povos que se aproximam do complexo alto-xinguano. Cabe observar, no entanto, que tal paralelo só se estabelece se levarmos em conta que "a produção desse complexo cultural não foi um processo de mão única" (FAUSTO, 2005: 22). Reconhece-se, assim, que os povos estrangeiros que pouco a pouco se integraram ao complexo alto-xinguano - isto é, adotaram modos de vida e elementos de seu universo mítico-ritual -, foram também agentes de sua produção. Conforme explica Fausto (2005: 23), "mesmo os ritos mais centrais do complexo xinguano, cuja origem remonta aos tempos míticos, trazem as marcas do processo histórico de hibridação que ocorreu nos últimos séculos". Voltando à dinâmica de circulação de vídeos, quero com isso indicar que, embora o fluxo de imagens do Alto para o Médio e Baixo Xingu seja mais intenso, o fluxo contrário também desempenha papel importante na constituição do que venho chamando de circuito imagético xinguano ${ }^{27}$. Esse circuito, por sua vez, opera em meio a essa contínua e multidirecional composição de "xinguanidade". A ausência de conexão à internet na maior parte do território (com exceção dos Polos-base e de algumas aldeias) não é impeditiva de tal circulação, que traça seus caminhos através do compartilhamento via bluetooth ${ }^{28}$.

Sejam em exibições coletivas no centro da aldeia, nos televisores das casas ou em pequenos grupos em torno de um smartphone, não é difícil observar como o posterior visionamento das filmagens implica em uma nova forma de apreciação dos rituais. Visto que, tanto no caso xinguano como no caso mebengokrê, essa circulação de vídeos "incrementa a dispersão, entre diferentes aldeias, de conhecimentos, formas rituais, designs de objetos cerimoniais, grafismos da pintura corporal, canções e passos de dança" (DEMARCHI, MADI, 2018: 47), é comum que o momento de assistir às festas desperte um minucioso julgamento dos elementos envolvidos em sua execução. Estimula-se, por meio das imagens, a criação de juízos estéticos acerca dos detalhes nas pinturas e nos adornos de cada indivíduo, bem como acerca da precisão dos gestos, sons e cantos performados. Um aspecto importante desse processo de formação de juízos diz respeito à observação dos elementos que apresentam alguma "inovação". No quarup yawalapití daquele ano,

27 Para o caso mebengokrê, Demarchi e Madi (2018: 47) falam na constituição de uma ampla "rede imagético-ritual interaldeã".

28 Demarchi e Madi falam de uma intensa circulação e troca de DVDs. Acredito que tal prática também vigorava entre os xinguanos, mas hoje foi quase totalmente substituída por outras mídias. 


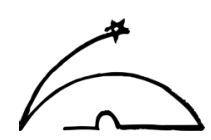

por exemplo, foi bastante comentado (bem como registrado em vídeo e fotografia) como alguns alto-xinguanos trouxeram, inscritas em sua pintura corporal, as palavras de ordem "Fora Temer".

A formação de juízos estéticos a partir das filmagens parece estar também associada a um "espírito de disputa" que vigora em ambos circuitos imagéticos aqui comentadas. Conforme relatam os pesquisadores (DEMARCHI, MADI, 2018: 49), assistir às "imagens dos parentes" permitia aos mebengokrê de determinada comunidade planejar melhor suas próprias festas tendo em vista "fazer mais bonito" que as outras aldeias. No Alto Xingu, as dinâmicas de competição estão estreitamente imbricadas na atividade ritual. Embora a pacificidade seja marca distintiva das relações que operam entre os povos pertencentes ao complexo alto-xinguano, estas também encerram uma dimensão agonística que, durante o Quarup, assume duas faces distintas. A mais evidente delas se expressa por meio das lutas de huka-huka, nas quais se confrontam lutadores "representantes" de cada um dos povos, constituindo, assim, uma espécie de "guerra simbólica" ou "guerra sem mortos" (GUERREIRO, 2015: 477 e 478). A outra face se expressa por meio de um extensivo circuito de trocas no qual "só se podem trocar objetos de grande valor, e idealmente apenas aqueles associados às identidades coletivas de cada povo, artigos de luxo dos quais são "donos", especialistas em sua produção" (GUERREIRO, 2015: 407). Se luta esportiva e troca, pensadas desde uma perspectiva da filosofia política ocidental, aparecem como uma supressão do estado de guerra e competição, a perspectiva xinguana se mostra "radicalmente diferente" (GUERREIRO, 2015: 414):

\footnotetext{
Primeiro porque a troca é que está associada à competição, seja porque ela é conduzida por "inimigos" em rituais cujo foco é esportivo, seja porque ela tem uma tendência agonística apenas parcialmente suprimida pela etiqueta dos encontros. Segundo, porque a troca não promove uma articulação orgânica de unidades previamente existentes (os indivíduos da teoria liberal do Estado), mas cria tais unidades a partir de relações de diferenciação mediadas por objetos. Idealmente só se trocam especialidades e não qualquer artigo de valor, porque a intenção dos trocadores é materializar seu grupo sob a forma de um objeto, marcando diferenças entre os trocadores. Mais do que marcar, a troca instaura tais diferenças.
}

Partindo desta proposição, sugiro que as disputas imagéticas xinguanas - estimuladas, sobretudo, pela circulação de vídeos de rituais - se inserem e transformam este sistema de trocas que, como vimos, é ele próprio movido por uma lógica de competição e de diferenciação. Há de se considerar, em primeiro lugar, que este sistema de trocas, tipicamente movido pelas especialidades produtivas alto-xinguanas, hoje proporciona o fluxo de novas produções, entre as quais o vídeo. Depois, temos que relações de troca que antes se circunscreviam ao complexo alto-xinguano hoje se difundem por toda a rede regional xinguana, constituindo, assim, um circuito imagético, não do Alto Xingu, mas de todo o TIX. Se, como vimos acerca da dinâmica alto-xinguana, a troca não promove uma articulação orgânica de unidades previamente existentes, mas cria tais 
unidades a partir de relações de diferenciação mediadas por objetos, cabe pensar também se os vídeos desempenhariam um papel significativo na composição das novas unidades que operam no, mais amplo, Território Indígena da Xingu.

É nesse sentido que, recuperando a proposta do início desse ensaio, penso que a rede regional xinguana se encontra hoje "amarrada", não apenas por trocas comerciais, casamentos, acusações de feitiçaria e experiências políticas conjuntas, mas também por uma experiência partilhada de uso do vídeo. Desde essa perspectiva, podemos pensar que se Menezes Bastos (1978) sugeria - há quatro décadas - que o ritual (em especial, a música) figura enquanto língua franca do complexo multilíngue alto-xinguano, talvez seja possível, hoje, esboçar uma concepção do vídeo enquanto uma espécie de língua franca do - mais amplo - Território Indígena do Xingu.

Deste ponto é possível retornar, por fim, à questão anteriormente levantada: diante de uma evidente intensificação e diversificação dos "temas" em direção aos quais se voltam as lentes e as telas xinguanas, o que faz com que o ritual siga configurando um momento privilegiado de produção imagética? O que faz com que os xinguanos se empenhem em filmar tanto - com quantos equipamentos e por quantos ângulos forem possíveis - e assistir tanto - longamente e repetidamente - às filmagens dos rituais? Embora considere que tal questão mereça um maior acúmulo de descrições etnográficas para ser respondida, me arrisco a esboçar uma explicação partindo da ideia de que os rituais, junto a seus múltiplos elementos estéticos (sejam eles visuais, sonoros, sensoriais ou gestuais), jamais são executados tendo em vista serem apenas vistos, isto é, configurarem-se simplesmente como uma objetivação (estética) da socialidade indígena. Trata-se de produzir festas bonitas, tendo em vista que

toda objetificação é, ao mesmo tempo, índice e causa de relações entre sujeitos: toda objetificação exibe, de alguma maneira, as relações que a produziram, enquanto cria ou afeta outras relações (pois só se objetifica algo a fim de exibi-lo ou oferecê-lo para alguém que se deseja afetar) (GUERREIRO, 2015: 430).

Acredito que seja justamente no entrecruzamento entre estética, ritual e agência que podemos situar a potência do registro audiovisual dos rituais e a intensidade de sua posterior circulação. Se os elementos estéticos dos rituais precisam ser exibidos para, então, produzirem efeitos sobre as relações com a alteridade, o audiovisual aparece como uma linguagem propícia à amplificação (no tempo e no espaço) de tais visualizações, e, consequentemente, de tais efeitos.

\section{Referências Bibliográficas}

BRASIL, André G. Rever, retorcer, reverter e retomar as imagens: comunidades de cinema e cosmopolítica. Galáxia. n.33, São Paulo, p.77-93, 2016. 


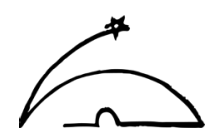

BRASIL, André; BELISÁRIO, Bernard. Desmanchar o Cinema: variações do fora-de-campo em filmes indígenas. Sociol. Antropol, v. 6, n.3, Rio de Janeiro, p.601-634, 2016.

CAIXETA DE QUEIRÓZ, Ruben. Cineastas Indígenas e Pensamento Selvagem. Devires. UFMG, v. 5, n. 2, p. 98-125, Belo Horizonte, 2008.

CARELLI, Vincent; GALLOIS, Dominique. Vídeo e Diálogo Cultural - Experiência do Projeto Vídeo nas Aldeias. Horizontes Antropológicos, v. 1, n. 2, p. 61-72, Porto Alegre, 1995.

CÓRDOVA, Amalia. Nomadic/Sporadic: The Pathways of Circulation of Indigenous Video in Latin America. Tese de doutorado. NYU, New York, 2015.

DEMARCHI, André; MADI DIAS, Diego (2018). Vídeo-Ritual: Circuitos Imagéticos e Filmagens Rituais entre os Mebêngôkre - Kayapó (Dossiê Olhares Cruzados). GIS - Gesto, Imagem E Som - Revista De Antropologia, v. 3, n. 1, p. 38-62, 2018.

FAUSTO, Carlos. Entre o passado e o presente: Mil anos de história indígena no Alto Xingu. Revista de Estudos e Pesquisas, FUNAI, Brasília, v. 2, n.2, p. 9-51, 2005.

FROTA, Mônica. Taking Aim e a Aldeia Global: A Apropriação Cultural e Política da Tecnologia de Vídeo pelos Índios Kayapós. Mnemocine. 1993.

GALLOIS, Dominique Tilkin (org.). Redes de relações nas Guianas. São Paulo: Associação Editorial Humanitas: Fapesp, 2005.

GINSBURG, Faye. Indigenous Media: Faustian Contract or Global Village? Cultural Anthropology, v. 6, n. 1, p. $92-112,1991$.

. Embedded Aesthetics: Creating a Discursive Space for Indigenous Media. Cultural Anthropology, v. 9, n. 3, p. 365-382, 1994.

. Indigenous Media from U-Matic to Youtube: Media Sovereignty in the Digital Age. Sociologia e Antropologia, v. 6, n. 3, p. 581-599, Rio de Janeiro, 2016.

GINSBURG, F.; ABU-LUGHOD, L.; LARKIN, B. Media Worlds: Anthropology on New Terrain. Los Angeles: University of California Press, 2002. p.75-89.

GOW, Peter. Cinema da Floresta. Filme, Alucinação e Sonho na Amazônia Peruana. Revista de Antropologia da 
USP. v. 36, p.37-54. São Paulo: Universidade de São Paulo, 1995.

GUERREIRO, Antonio. 2015. Ancestrais e suas sombras: uma etnografia da chefia Kalapalo e seu ritual mortuário. Campinas: Editora da Unicamp.

Do que é Feita uma Sociedade Regional? Lugares, Donos e Nomes no Alto Xingu. ILHA. v. 18, n. 2, p. 23-55, 2016.

HECKENBERGER, Michael. The Ecology of Power: Culture, Place, and Personhood in the Southern Amazon, A.D. 1000-2000. New York and London: Routledge, 2005.

LATOUR, Bruno. Jamais fomos modernos: ensaio de antropologia simétrica. Tradução de Carlos Irineu da Costa. 1. Ed. Rio de janeiro: Ed. 34, 1994.

MENEZES BASTOS, Rafael J. A musicológica kamayurá: para uma antropologia da comunicação no Alto-Xingu. Brasília: Fundação Nacional do Índio, 1978.

Indagação sobre os Kamayura, o Alto Xingu e outros nomes e coisas: Uma etnologia da sociedade Xinguara. Anuário Antropológico, 1994.

SERBER, Luiza de Paula Souza. Regimes de produção e circulação imagética no Território Indígena do Xingu. Dissertação de Mestrado (Antropologia Social), Universidade Estadual de Campinas, 2018.

TURNER, Terence. Defiant Images: The Kayapo Appropriation of Video. Anthropology Today. v. 8, n. 6, p. 5-16, 1992.

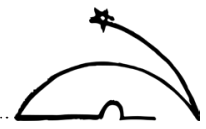

